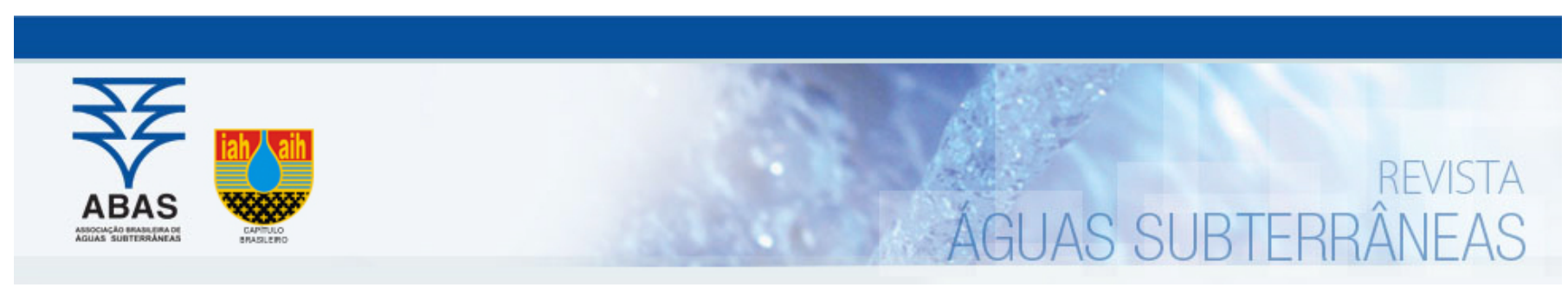

Artigos

\title{
Modelo conceitual da degradação de poliacrilamidas (PAM) em compostos nitrogenados
}

\section{A conceptual model for polyacrylamid (PAM) degradation in nitrogen compounds}

\author{
Aline Diorio dos Santos; Rosely Aparecida Liguori Imbernon²; Anibal Bem David Albino Muchimbane³ Elias Hideo Teramoto4; Hung Kiang \\ Chang 4
}

1 Universidade Estadual Paulista "Júlio de Mesquita Filho". Programa de Geociências e Meio Ambiente, São Paulo.

2 Universidade de São Paulo (USP). Escola de Artes, Ciências e Humanidades - EACH.

3 Diretoria Nacional de Geologia, Moçambique.

4 UNESP - Universidade Estadual Paulista "Júlio de Mesquita Filho". Centro de Estudos Ambientais (CEA) e Laboratório de Estudos de Bacias (LEBAC).

\} \text { santo.diorio@gmail.com, imbernon@usp.br,anibalmuchi@yahoo.com.br, teramoto@rc.unesp.br,chang@rc.unesp.br }

Resumo

Palavras-chave:

lodo ETA.

Poliacrilamida (PAM).

Compostos Nitrogenados.

Modelo Conceitual.

Esse estudo teve como objetivo avaliar os impactos gerados por polímero Poliacrilamida (PAM), encontrados em resíduos de estação de tratamento de água. A degradação do PAM pode estar associada à presença de compostos nitrogenados na água, como amônio, nitratos e nitritos, sendo essencial a avaliação da degradação deste polímero. A metodologia envolveu a elaboração de um Modelo Conceitual para a disposição de lodo de ETA em aterros tecnogênicos, com enfoque em poliacrilamidas e sua degradação em compostos nitrogenados. O modelo foi validado a partir de dados observados em um estudo de caso desenvolvido em Taiaçupeba, Suzano, SP. Observou-se que no processo de nitrificação, por via aeróbia, o ín amônio é oxidado a nitritos e posteriormente a nitratos; e por via anaeróbia, uma reação anamox, em que amônio é oxidado e nitrito reduzido, liberando gás nitrogênio em ambiente redutor. Adicionalmente, foram observados íon amônio, óxido de manganês e hidróxido de ferro (abundantes no solo in situ e também no lodo) sendo oxidados a nitrogênio gasoso e consumindo íons $\mathrm{H}+$ no meio. A variação do nível de água do aquífero freático pode influenciar as concentrações observadas em razão do incremento da espessura da zona saturada, possibilitando o contato com camadas superficiais de PAM.

Abstract

Keywords:

ETA sludge.

Polyacrylamide (PAM).

Nitrogen compounds.

Conceptual Model.

Revisado por pares.

Recebido em: 13/07/2018.

Aprovado em: 23/11/2018.

\begin{abstract}
This study aimed to evaluate the impacts generated by polymer Polyacrylamide (PAM), found in wastewater treatment plant. The degradation of MAP can be associated with the presence of nitrogenous compounds in water, such as ammonium, nitrates and nitrites, and it is essential to evaluate the degradation of this polymer. The methodology involves the proposal of a Conceptua Model for the disposal of ETA sludge in technogenic landfills, with a focus on polyacrylamides and their degradation in nitrogen compounds. The model was validated from data observed in a case study of ETA sludge from Taiaçupeba, Suzano, SP. It was observed that the nitrification process, by aerobic route, the ammonium ion is oxidized to nitrites and later to nitrates; and anaerobically, an anamox reaction, in which ammonia is oxidized and nitrite reduced, releasing nitrogen gas in a reducing environment. In addition, ammonium ion, manganese oxide and iron hydroxide (abundant in the soil in situ and also in the sludge) were observed, being oxidized to gaseous nitrogen and consuming $\mathrm{H}+$ ions in the medium. The variation of the water level of the water table can influence the concentrations observed due to the increase in the thickness of the saturated zone, allowing the contact with superficial layers of MAP.
\end{abstract}

DOI:http:/dx.doi.org/10.14295/ras.v32i3.29181

\section{INTRODUÇÃO}

Em estações de tratamento de água (ETA) são geradas grandes quantidades de resíduos como subproduto, o lodo de ETA, em geral, nos decantadores e filtros, que não podem ser descartados aleatoriamente, e tem se configurado como problema ambiental a ser equacionado. No Brasil, o Censo de 2010 mostrou que entre as cidades com mais de 300.000 habitantes, $85,7 \%$ têm ETA's convencionais, e a maioria dos resíduos gerados pelos sistemas de tratamento são descartados diretamente no meio ambiente.
Os sistemas de potabilização de água para abastecimento público empregam agentes floculantes em larga escala, como sais de ferro, alumínio ou polímeros sintéticos para coagulação química (SLATTER, 1997), processos que gera grandes quantidades de resíduos sólidos, o lodo de ETA. Esse lodo possui características bastante variadas, dependendo das características físico-químicas da água bruta, das quantidades dosadas dos produtos químicos utilizados, da forma de lavagem dos decantadores, entre outros fatores (FREITAS et al., 2004; TSUTIYA \& HIRATA, 2001). 0 teor máximo de umidade no lodo produzido em ETA's, geralmente, atinge $99 \%$ após a 
sedimentação secundária e 95\% a 98\% após o espessamento (ZHOU et al., 2014).

Os lodos de ETA's são compostos complexos em suas estruturas, pois possuem morfologia irregular, muitas vezes com características reológicas de fluído não-newtoniano e ampla distribuição de tamanho de partículas (SLATTER, 1997; DENTEL, 1997). Desta forma, a aplicação de polímeros do tipo poliacrilamida (PAM), altamente difundido em ETA's, e no processo de disposição final do lodo gerado, é amplamente utilizado para auxiliar na separação sólido-líquido através da neutralização de carga de superfície e da ponte interpartícula (MOUSSAS \& ZOUBOULIS, 2009).

O PAM não tem sido classificado como um composto de interesse em razão da sua não toxicidade em sua forma polimérica original (SEYBOLD, 1994). O risco ambiental decorrente da disposição do PAM no meio ambiente tem sido atribuído exclusivamente à presença de acrilamida residual presente (SEYBOLD, 1994; GUÉZENNEC, 2015), uma vez que a acrilamida é classificada como uma substância carcinogênico (nível 2), mutagênico (nível 2) e reprotóxico (nível 3) (MOLAK, 1991).

Tradicionalmente, o PAM tem sido considerado uma substância altamente recalcitrante e não metabolizável por microorganismos (ELMAMOUNI, 2002). A despeito de sua classificação como material recalcitrante, diversos trabalhos, incluindo Nakamiya \& Kinoshita (1995), Wen et al. (2010), Dai et al. (2015) e Joshi et al. (2017), têm demonstrado que o PAM pode ser degradado pelo metabolismo microbiano. Wen et al. (2010) demonstraram experimentalmente que a PAM pode ser degradado por cepas bacterianas com uma alta capacidade ( $>70 \%)$ empregando este composto como fonte única de carbono. Nakamiya \& Kinoshita (1995) identificou as espécies Enterobacter agglomerans e Azomonas macrocytogenes como espécies capazes de degradar entre 15 e 20\% da concentração inicial de PAM. Testes laboratoriais conduzidos por Wen et al. (2010) verificou que a biodegradação da PAM pelas cepas Bacillus cereus e Bacillus flexu foram eficientes, com $70 \%$ da PAM sendo consumida em 72 horas. 0 trabalho de Zhou et al. (2012) sugere que a degradação da PAM não é conduzida por uma única espécie e, sim, por um consórcio de bactérias. Zhou et al. (2012) verificaram que comunidades compostas majoritariamente por bactérias filamentosas e bacilos, utilizaram o PAM como única fonte de carbono e nitrogênio e degradaram o PAM com elevada taxa de biodegradação, na qual a concentração de PAM diminuiu de 66,7 para $32,9 \mathrm{mg}$ $\mathrm{L}^{-1}$ em $24 \mathrm{~h}$.

O estudo da degradação em meio ácido demonstrou que as alterações macroscópicas em diferentes soluções aquosas de PAM modificadas, em diferentes concentrações de ácido, variaram muito (PEI et al. 2016). Embora muitos estudos sobre degradação de PAM estejam disponíveis na literatura, a compreensão da degradação da PAM em subsuperfície e a consequente liberação para a água de compostos provenientes de sua degradação, bem como as implicações ambientais desta degradação devem ser compreendidas. Por esta razão, a elaboração de um Modelo Conceitual dos cenários de contaminação associados às ETAS deve ser elaborada para prever os eventuais efeitos ambientalmente adversos. Com base em infor- mações disponíveis na literatura, este trabalho pretendeu elaborar um modelo conceitual com as possíveis reações, mecanismos geoquímicos e hidrológicos atuantes na degradação da PAM. Para testar a viabilidade do modelo conceitual concebido no presente trabaIho, esta foi aplicada em uma área com disposição lodo da ETA-Taiaçupeba (Suzano-SP) contendo PAM.

\subsection{MATERIAIS E MÉTODOS}

\section{1. Área de estudo}

A área de estudo está inserida na região compreendida pela barragem de Taiaçupeba, município de Suzano, Região Metropolitana de São Paulo (RMSP), onde se localiza a Estação de Tratamento de Água - ETA Taiaçupeba, gerenciada pela SABESP. A barragem compõe o Sistema Produtor do Alto Tietê - SPAT, e durante muitos anos o lodo gerado na ETA Taiaçuepeba foi depositado no próprio reservatório, à jusante da captação da ETA. A partir de fevereiro de 2005, o lodo outrora lançado no lago, foi retirado e acumulado em diques na área ao lado do vertedouro da barragem próximo ao maciço, formando um depósito tecnogênico. O lodo está submetido a processos de degradação mecânica e química promovidas pelo sol e pelas chuvas que lixiviam e carreiam os metais pesados no solo e no lençol freático. 0 aquífero local é representado por depósitos aluvionares quaternários, com predomínio de sedimentos argilo-arenosos e areno-siltosos.

\subsection{Levantamentos geofísicos para dimensionamento do depósito}

A instalação de poços de monitoramento foi precedida por etapa de levantamentos geofísicos, realizados no interior do aterro, por meio de sondagens elétricas verticais (SEV), com o resistivímetro ABEM SAS 200, foi possível determinar a profundidade do aquífero. Por intermédio do levantamento Eletromagnético (EM), realizado com o equipamento EM-31 da Geonics, foi realizada a determinação da área com anomalias geofísicas, provavelmente associadas ao maior volume de lodo depositado. Os ensaios geofísicos serviram como critério para a distribuição dos poços de monitoramento a serem instalados, bem como seu perfil construtivo em função de uma maior concentração em profundidade do lodo transposto para a área.

\subsection{Amostragem de água}

Doze poços de monitoramento foram instalados na área: dentre esses, oito foram instalados no interior do aterro tecnogênico, onde o resíduo foi disposto (F1, F2, F8, F9, F10, F11, F12 e F13) e quatro fora (F5a, F6, F7 e F16), conforme apresentado na Figura 1. 0 poço F6 foi instalado às margens do antigo leito do rio Taiaçupeba Mirim, para servir como referência de local isento da influência do lodo, representativo do background local. Dos três outros poços na área externa ao dique de resíduo, o F7 foi instalado na estrada de acesso aos diques, entre a área de estudo e o maciço da barragem, o poço F5a e F16 foram instalados à norte do dique, aproximadamente $1,5 \mathrm{~m}$ abaixo do nível de disposição do lodo. 


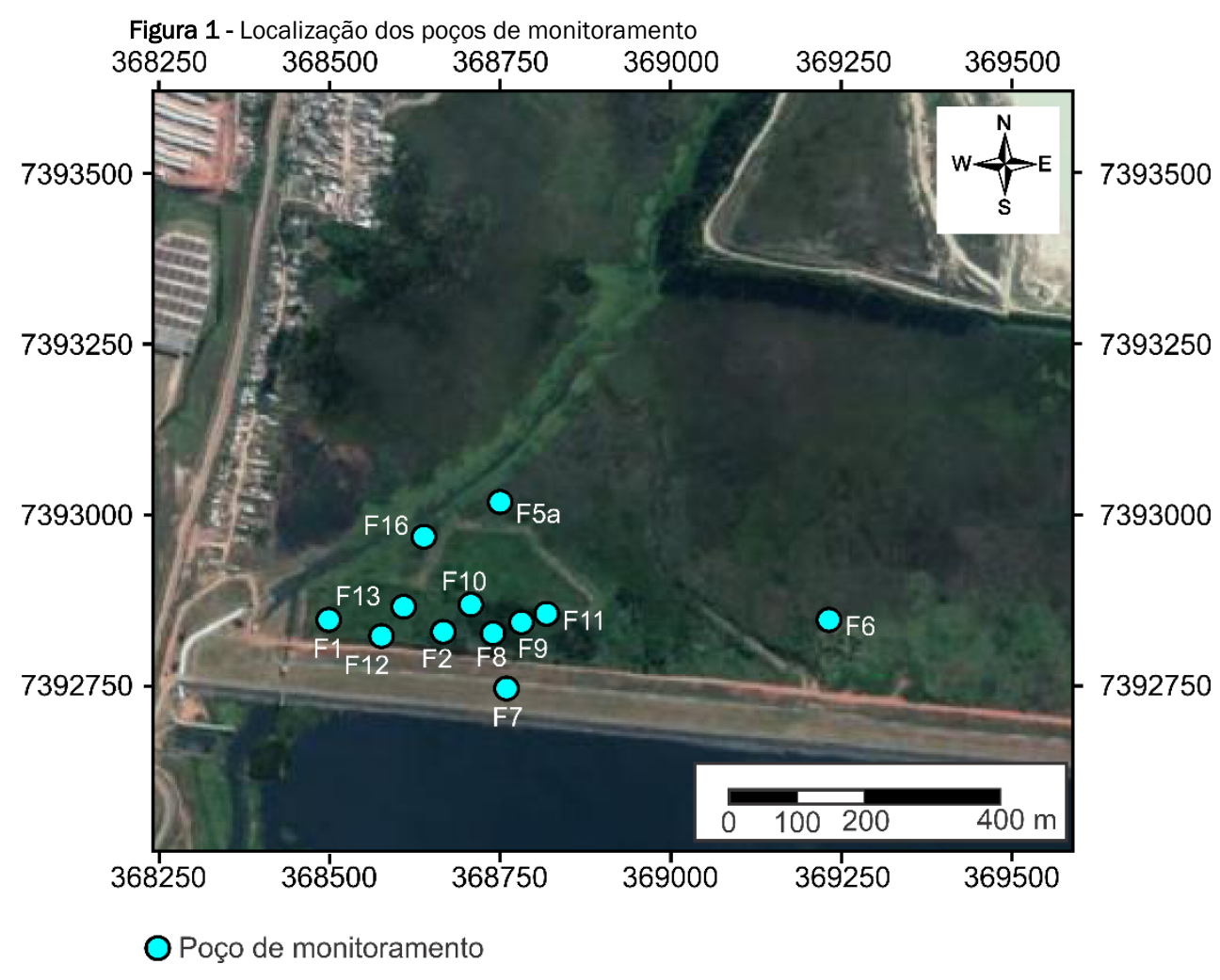

Nas etapas de coleta, em abril e novembro de 2014 , foram feitas as amostragens de água subterrânea nos poços de monitoramento e amostragem de águas superficiais nos canais que circundam o depósito de lodo (canal do vertedouro e no antigo leito do rio Taiaçupeba Mirim).

A amostragem de água foi feita seguindo-se a metodologia da CETESB (2001), através da purga dos poços, coleta, preservação e transporte. A purga foi realizada um dia antes da coleta, quando foi medido o nível estático de cada do poço. Na coleta foi utilizada bomba peristáltica para coleta de no mínimo três vezes o volume de água do poço, fazendo com que a água amostrada fosse representativa do aquífero estudado.

\subsection{Modelo Conceitual}

A consulta de trabalhos relevantes, que descrevem a biodegradação da poliacrilamida, permitiu a identificação dos possíveis mecanismos associados à degradação da poliacrilamida em subsuperfície. A quase totalidade destes trabalhos abordam experimentos com microcosmos e a identificação dos microorganismos que promovem a degradação destes compostos. No entanto, o comportamento dos metabólitos provenientes da degradação da PAM, as possíveis implicações geoquímicas da presença destes compostos na água e os fatores que governam tais transformações não foram anteriormente abordadas.

Para prever o comportamento da PAM como fonte de contaminação subsuperficial, foi elaborado um modelo conceitual contemplando a liberação de compostos nitrogenados na água baseando-se em informações presente na literatura (JOSHI et al. 2017, NAKAMIYA \& KINOSHITA 1995, WEN et al. 2010, ZHOU et al. 2012, DAl et al. 2015, EL-MAMOUNI et al. 2002 e PEl et al. 2016).

O modelo conceitual elaborado também contempla a posterior transformação dos compostos gerados pela degradação da PAM em ambientes oxidante e anóxico, enfatizando-se o controle exercido

pela flutuação do nível d'água. 0 modelo conceitual procedeu-se à comparação com os resultados das duas campanhas de amostragem de água subterrânea conduzidas na área de estudo, além dos resultados analíticos apresentados as descrições de sondagens e os resultados da medição do nível d'água, conduzidas em abril e novembro de 2014.

\section{RESULTADOS}

\subsection{Modelo Conceitual da degradação de poliacrilamidas e forma- ção dos compostos de $N$}

De acordo com Joshi et al. (2017) os polímeros de alto peso molecular como PAM são incapazes de passar através de membranas biológicas; portanto, apenas algumas cepas bacterianas mostraram degradação parcial desses compostos. Ainda de acordo com estes autores, a biodegradação aeróbicas ou anaeróbicas da PAM e seus derivados são iniciados pela enzima amidase, sendo degradadas parcial ou totalmente por uma matriz de diferentes enzimas. 0 principal produto intermediário proveniente da degração da PAM foi o ácido poliacrílico, com baixo peso molecular.

A despeito da comprovação da capacidade de certos microorganismos em degradar a poliacrilamida, a rota metabólica com todas as etapas de transformação do PAM ao longo de sua degradação não é perfeitamente compreendida (JOSHI et al., 2017). Joshi et al. (2017) inferiu que a rota metabólica da degradação da PAM envolvia a produção da acrilamida. Entretanto, diversos autores, tais como Nakamiya \& Kinoshita (1995), Wen et al. (2010), ZHOU et al. (2012), Dai et al. (2015), que estudaram o metabolismo bacteriano da PAM pela hidrólise do grupo amida não detectaram a produção do monômero de acrilamida. Ainda que a rota metabólica e as enzimas utilizadas em cada etapa da degradação microbiana da PAM não tenham sido plenamente elucidadas, é possível assumir que a degradação da PAM é responsável pela produção de ácidos orgânicos, tais como propianato e lactato, associados ao íon amônio. 
Durante o transporte da água da área contendo os produtos solúveis provenientes da degradação da PAM, tal como o amônio podem ser oxidados para nitrito (Eq. 1) pelas bactérias do gênero Nitrosomas e, posteriormente, o nitrito é oxidado para nitrato (Eq. 2) pelas bactérias do gênero Nitrobacter (THAMDRUP, 2012), desde que existam concentrações favoráveis de oxigênio dissolvido (OD).

$$
\begin{gathered}
\mathrm{NH}_{4}^{+}+\frac{3}{2} \mathrm{O}_{2} \rightarrow \mathrm{NO}_{2}^{-}+\mathrm{H}_{2} \mathrm{O}+\mathrm{H}^{+} \\
\mathrm{NO}_{2}^{-}+\frac{1}{2} \mathrm{O}_{2} \rightarrow \mathrm{NO}_{3}^{-}
\end{gathered}
$$

Em condições anóxicas (ausência de oxigênio associado a presença de nitratos), os nitratos são utilizados por bactérias heterotróficas como o aceptor de elétron em substituição ao oxigênio, sendo tal processo denominado desnitrificação. 0 íon nitrato, portanto, é reduzido para $\mathrm{N}_{2}$ (Eq. 3).

$$
3 \mathrm{NO}_{3}^{-}+2 \mathrm{H}^{+} \rightarrow \mathrm{N}_{2}+2 \mathrm{O}_{2}
$$

Semelhante à desnitrificação, a Redução Dissimilatória de Nitrato para Amônio (RDNA) também envolve a redução de $\mathrm{NO}_{3}^{-}$em condições anóxicas para $\mathrm{N}_{2}$. Quando excesso de $\mathrm{NO}_{3}$ - está presente, a desnitrificação é o processo dominante da redução de $\mathrm{NO}_{3}$. Em ambientes com baixas concentrações de $\mathrm{NO}_{3}^{-}$, mas com fontes acessíveis de carbono, a RDNA é o processo dominante de oxidação da matéria orgânica, podendo ser representado pela Eq. 4:

$$
2 \mathrm{H}^{+}+\mathrm{NO}_{3}^{-}+2 \mathrm{CH}_{2} \mathrm{O} \rightarrow \mathrm{NH}_{4}^{+}+2 \mathrm{CO}_{2}+\mathrm{H}_{2} \mathrm{O}
$$

Sob condições anaeróbicas, $\mathrm{NH}_{4}{ }^{+}$é oxidado e $\mathrm{NO}_{2}^{-}$reduzido, podendo formar $\mathrm{N}_{2}$. Além da desnitrificação, a Oxidação Anaeróbica de Amônio (Anamox) é um dos poucos processos naturais que podem remover o nitrogênio de subsuperfície (THAMDRUP, 2012) (Equação 5):

$$
\mathrm{NH}_{4}^{+}+\mathrm{NO}_{2}^{-} \rightarrow \mathrm{N}_{2}+2 \mathrm{H}_{2} \mathrm{O}
$$

As águas subterrâneas contendo amônio, nitrito e baixa disponibilidade de oxigênio fornecem o ambiente ideal para 0 crescimento de bactérias anamox (que se reproduzem em condições anaeróbias), porém é escassa a literatura sobre o tema.

A nitrificação requer maior quantidade de oxigênio do que para a remoção da matéria carbonácea, pois, em sua fase de absorção, que precede o metabolismo, pode armazenar energia de alguma forma até que o oxigênio se torne disponível novamente. Em contraste, a nitrificação termina no instante em que o oxigênio se reduz abaixo do nível crítico, retomando seu início tão logo o OD seja elevado no meio. Neste cenário, a inclusão de bactérias Anamox, que se reproduzem em condições anaeróbias, em que amônio é oxidado e nitrito reduzido liberando gás nitrogênio.

\subsection{Redução do Fe e Mn do sedimento}

A redução do $\mathrm{NH}_{4}{ }^{+}$para $\mathrm{N}_{2}$ também pode ser mediada pela redução do ferro e mangânes presentes nos sedimentos na forma de óxidos e hidróxidos. A redução do $\mathrm{NH}_{4}{ }^{+}$pela redução do óxido de ferro e manganês são apresentadas, respectivamente, nas Equações 6 e 7.

$$
\begin{gathered}
2 \mathrm{NH}_{4}^{+}+6 \mathrm{FeOOH}+10 \mathrm{H}^{+} \rightarrow \mathrm{N}_{2}+6 \mathrm{Fe}^{2+}+12 \mathrm{H}_{2} \mathrm{O} \\
2 \mathrm{NH}_{4}^{+}+3 \mathrm{MnO}_{2}+4 \mathrm{H}^{+} \rightarrow \mathrm{N}_{2}+3 \mathrm{Mn}^{2+}+6 \mathrm{H}_{2} \mathrm{O}
\end{gathered}
$$

No modelo proposto, são apresentadas duas vias de dissociação dos compostos nitrogenados, sendo consideradas tanto a via aeróbia quanto a anaeróbia, de acordo com a disponibilidade de oxigênio. 0 modelo conceitual é apresentado na Figura 2, onde os conceitos anteriormente discutidos são reunidos de forma sintetizada.

Figura 2. Cadeia de reações relacionadas à degradação de poliacrilamidas (PAM) em subsuperfície

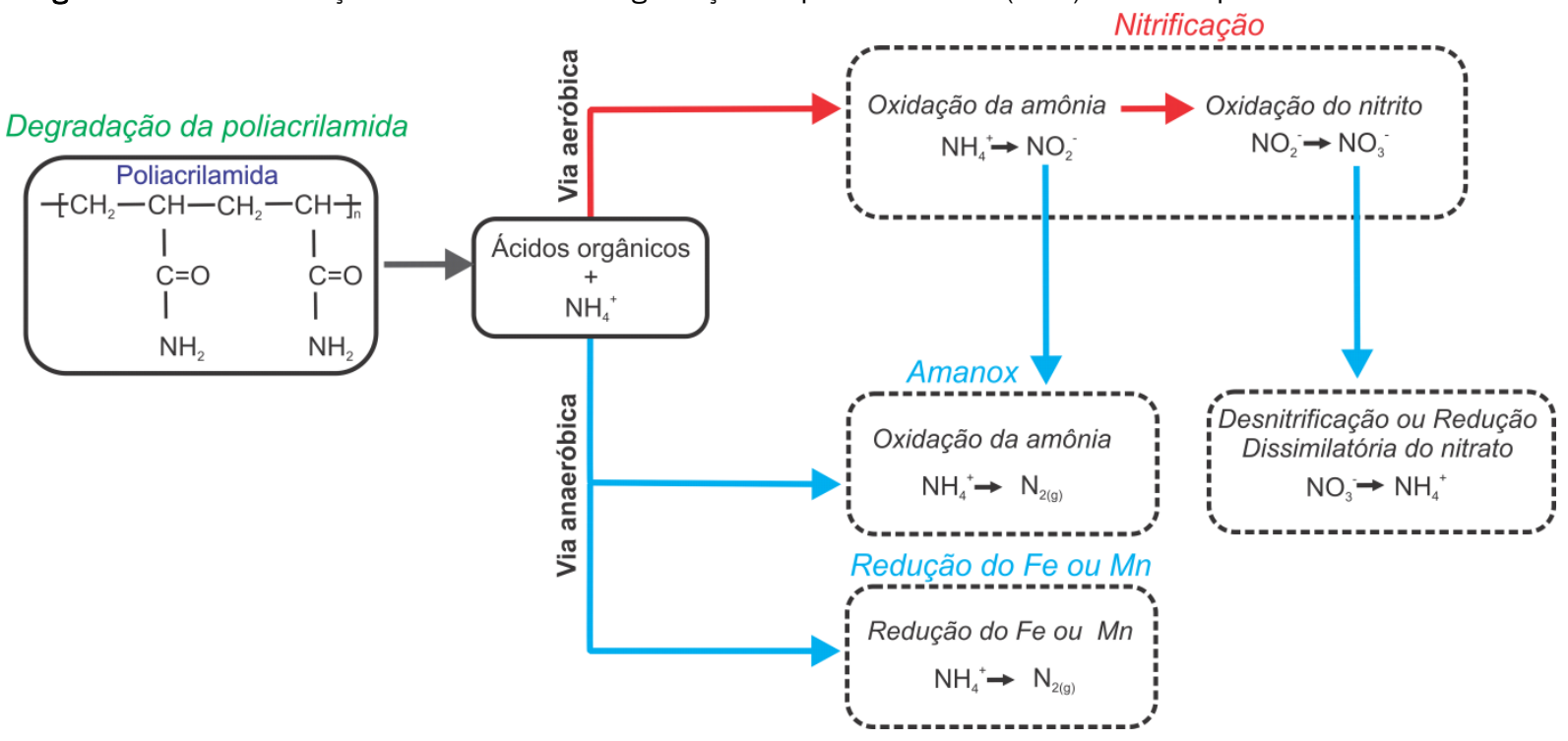




\subsection{Influência da flutuação do nível de água nas concentrações dos compostos nitrogenados}

As variações cíclicas da quantidade de água que ingressa nos aquíferos por recarga promove a variação do nível d'água. Em períodos onde existe a recarga do aquífero há uma elevação do nível de água, enquanto nos períodos de estiagem, existe uma queda do nível de água, gerando ciclos alternados de ascensão e queda do nível d’água.

As reações de oxirredução das espécies nitrogenadas (Eq. 1 a 7) produzidas pela degradação da (PAM) são controladas pela disponibilidade de oxigênio dissolvido na água subterrânea. Por esta razão, é esperado que o ingresso sazonal de oxigênio durante os períodos de recarga do aquífero promova mudanças significativas nas condições redox do aquífero e, consequentemente, modifique as reações de oxirredução operantes da mesma maneira que cinética das mesmas.

Além das modificações nas condições redox do aquífero, é esperado que a ascensão do nível d'água associado ao evento de recarga do aquífero promova efeitos distintos na região do aquífero contendo o lodo enterrado contendo PAM e na fase dissolvida dos compostos nitrogenados (Figura 3). No caso da região contendo o lodo enterrado, a ascensão do nível d'água promove aumento na espessura da zona saturada do aquífero, fazendo com que maior quantidade de lodo com PAM, presente no aterro, esteja em contato com a água subterrânea. Por consequência, ocorre maior liberação de amônio para a água subterrânea. Em contrapartida, a ascensão do nível d'água promove a diluição dos compostos nitrogenados na pluma de fase dissolvida destes compostos, além de propiciar a ocorrência de reações de nitrificação do $\mathrm{NH}_{4}{ }^{+}$.

Figura 3.- Modelo conceitual com os efeitos esperados da ascensão do nível d'água para a liberação de compostos nitrogenados e o comportamento das plumas destes compostos

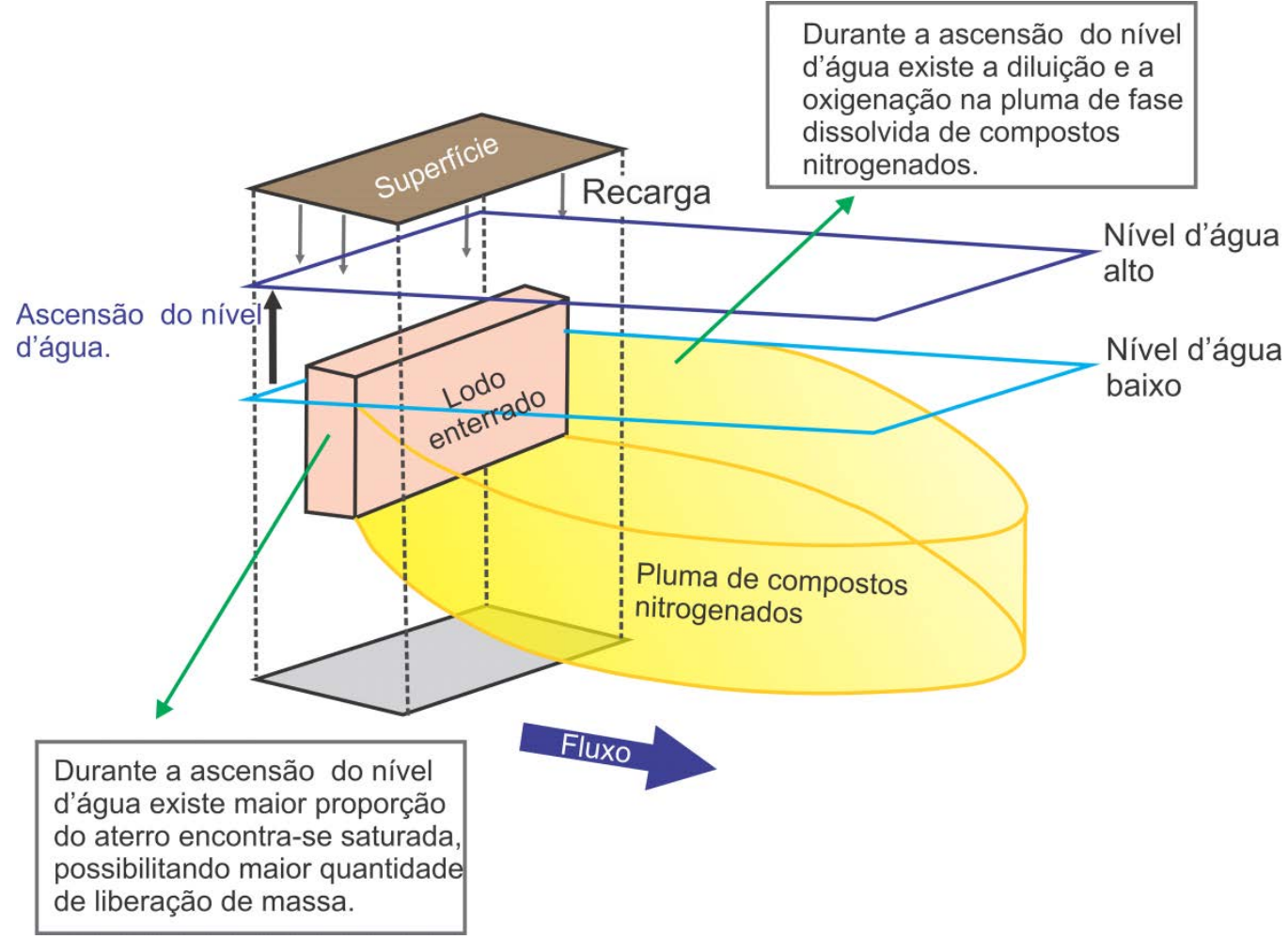

\subsection{Validação do Modelo Conceitual}

Em ambientes com grandes quantidades de matéria orgânica enterrada, como o dique de lodo na área de estudo, pode haver deterioração do meio pela ocorrência de processos biológicos responsáveis pela produção elevada de $\mathrm{NH}_{4}{ }^{+}$, que migra para a água subterrânea. Tendo em vista que o amônio pode ser oxidado para nitrito e nitrato por via aeróbica, a presença dessas espécies químicas é um forte indicador de que o conjunto de reações previstas no modelo conceitual esteja ocorrendo. A Figura 4 apresenta as concentrações dos compostos nitrogenados em duas campanhas de amostragem realizadas, e as concentrações determinadas indicam que as reações de oxidação do amônio ocorreram na área de estudo.

A Figura 5 apresenta a seção lito-estratigráfica da área utilizada para validação do Modelo, onde são apresentados os sedimentos encontrados na área de estudo, lentes com presença de lodo e a relação entre os níveis de água da primeira e da segunda campanha de monitoramento. Observa-se que os poços de monitoramento apresentam nível de água mais raso na primeira campanha do que na segunda, entrando em contato com camadas superficiais do aterro que apresentam poliacrilamida, que antes estavam acima do nível de água. 


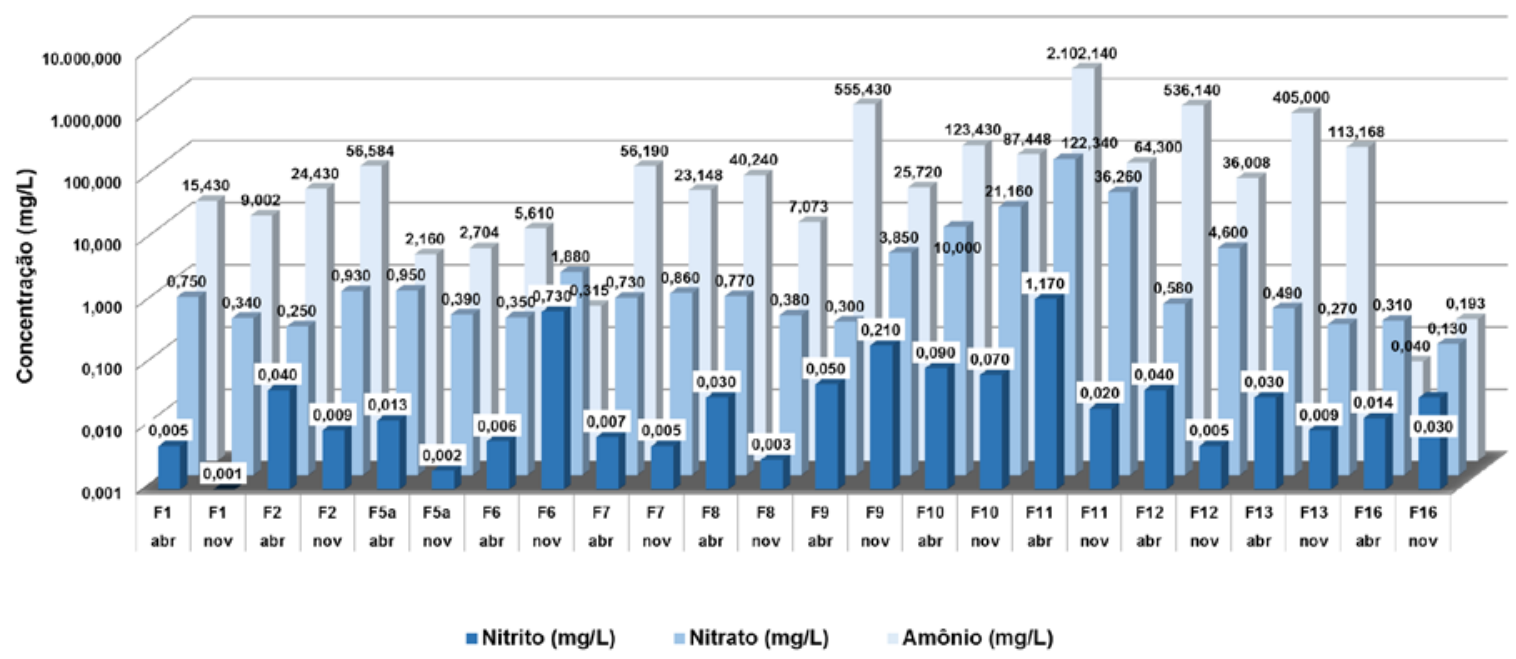

Figura 5 - Seção lito-estratigráfica A-A`e B-B
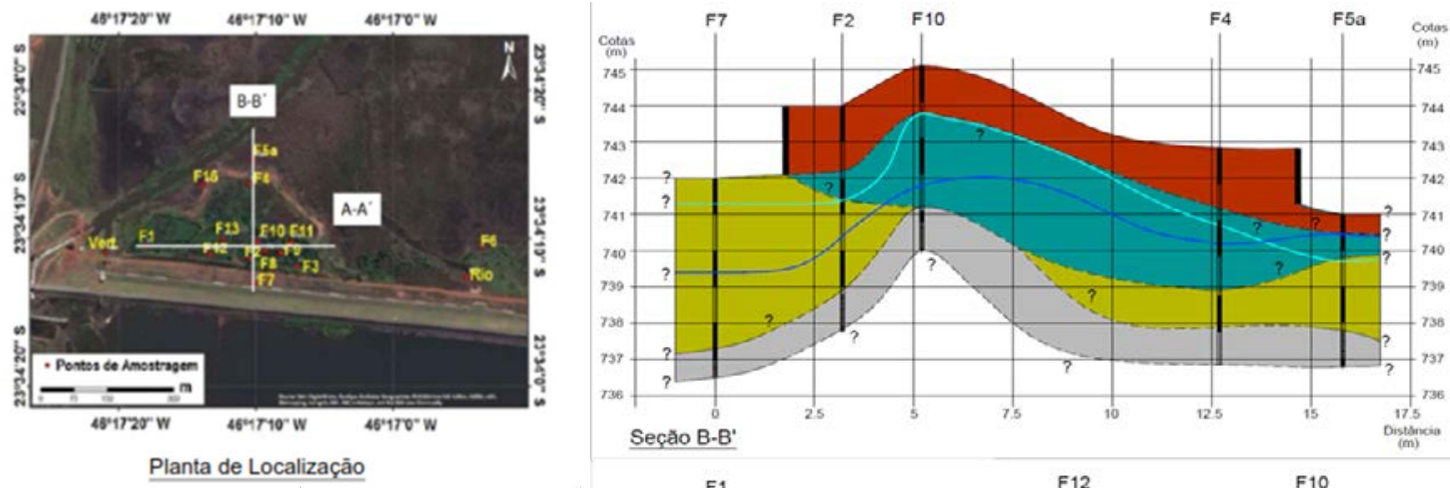

Legenda

NA - Linha do Nivel đágua - Abril14

NA - Linha do Nivel đđÁgua - Novembro/14

Dique

Silte arenoso, silte argiloso/ argila siltosa, cor castanho escuro. Material de cor preta, textura viscosa (lodo).

Argila arenosa, silte argiloso/ Argila siltosa, areia sittosa, areia media a fina, cor vermelho $\mathrm{C}$ tons alaranjados. Areia siltosa, argila siltosa/ silte argiloso/ areia argilosa, areia média a fina, cor acizentad-

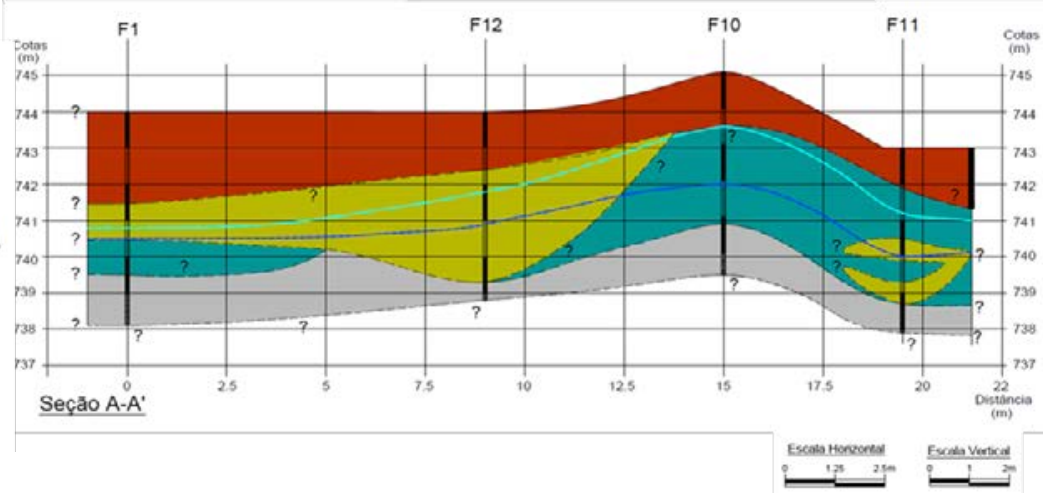

\section{DISCUSSÕES}

Diante da escassez de informações referentes ao comportamento do PAM como possível fonte de contaminação em subsuperfície, este trabalho pretendeu elaborar um modelo conceitual a partir de informações proveniente de trabalhos anteriores. A partir do estudo de caso de contaminação associado à disposição inadequada de lodo contendo poliacrilamida (PAM) em aterro tecnogênico, foi possível elaborar um modelo conceitual, cujas premissas apresentadas buscaram explicar as elevadas concentrações de compostos nitrogenados medidas em duas campanhas de amostragem realizadas.

A presença de nitratos indica a ocorrência do processo de nitrificação do amônio, em que o mesmo é consumido gerando como produtos de degradação ácidos orgânicos e nitritos e, na 
sequência, nitratos, devido ao processo de nitrificação em meio aeróbico. Como pode ser observado na Figura 5, ocorre uma tendência geral de as concentrações dos íons amônio, principalmente, e de nitrato e nitrito serem maiores na primeira campanha (período seco) do que na segunda campanha de monitoramento (período chuvoso). Esse fato pode estar associado à maior lixiviação dos íons presentes no lodo para a água subterrânea, devido ao período chuvoso.

Essas concentrações podem estar associadas a processos por via aeróbia, da degradação do amônio para nitritos, que geralmente se apresentam em menor quantidade, já que o processo de degradação das Nitrosomonas - que convertem amônio a nitrito - é mais lento do que a das Nitrobacter - que convertem nitrito em nitratos.

As concentrações elevadas de amônio e nitrito na primeira campanha de monitoramento pode ser explicada pela oxidação de amônio e redução de nitrito em meio anaeróbio, pela reação anamox. Esta situação está em concordância com o meio redutor observado na primeira campanha, conforme previsto no modelo conceitual. Ressalta-se que podem estar ocorrendo tanto os processos aeróbios quanto anaeróbios, conforme a disponibilização de OD no meio.

A flutuação do nível de água no aquífero pode influenciar as concentrações observadas, uma vez que a espessura do aquífero livre pode se tornar maior com a recarga, entrando em contato com níveis mais superficiais de PAM (que antes estavam acima do nível de água), ocorrendo maior lixiviação dos íons presentes nestas camadas e consequente aumento das concentrações dos compostos nitrogenados (produtos da degradação das PAM). Deste modo, as amostras de água coletadas após o período chuvoso, em abril, tendem a apresentar maior quantidade de íons dissolvidos e maior concentração dos subprodutos de degradação da PAM (compostos nitrogenados) que aquelas amostradas após período com baixa pluviometria (inverno), em novembro.

Os poços situados no dique apresentaram maiores concentrações que os poços de fora do dique, devido à presença de PAM, observando-se concentrações maiores em abril. Esse fenômeno pode estar ocorrendo em conjunto com os processos biológicos descritos anteriormente. Nos poços externos ao dique, sem a presença de PAM que contribua para lixiviação de íons e consequente aumento de massa, a espessura de água no período chuvoso propiciou a diluição das concentrações, apresentando, portanto, menores concentrações dos compostos nas amostras de água coletadas em abril do que nas coletadas em novembro.

Portanto, a correlação das concentrações dos compostos nitrogenados com o nível de água observado no estudo de caso valida os conceitos teóricos apresentadas no Modelo Conceitual, associando a lixiviação das camadas contendo PAM com o aumento das concentrações dos compostos nitrogenados e a variação do nível de água nos períodos chuvoso e seco.

Ressalta-se que existem muito poucos dados a respeito das taxas de processos biológicos de degradação/dissociação do ín amônio na zona saturada. A literatura evidencia que esses mecanismos, tanto em meio aeróbio quanto anaeróbio, podem desempenhar um papel significativo na diminuição das concentrações de $\mathrm{NH}_{4}+$ em águas subterrâneas contaminadas, porém estudos com maior quantidade de dados de ensaios hidrogeológicos e geotécnicos se fazem necessários para meIhor entendimento das relações observadas, maior detalhamento e calibração do modelo. Além disso, a comparação entre dados obtidos em campanhas de amostragem sazonais (período chuvoso e seco) também são necessários.

Torna-se, portanto, indispensável a discussão sobre quais tipos de polieletrólitos podem ser utilizados no sistema de tratamento de água, uma vez que a PAM utilizada no processo de tratamento pode degradar-se em amônio e este, por sua vez, em nitrato por via aeróbia, contaminando o aquífero local. Ou seja, a PAM não se comporta como resíduo inerte como preconizado pelo mercado e por alguns autores.

Cabe mencionar que a análise molecular metagenômica e de RNA $16 S$ podem contribuir significatemente para a compreensão de como os processos metabólicos envolvidos na degradação do PAM e da subsequente transformação de seus produtos de degradação. Entretanto, é possível inferir que comunidade de bactérias podem variar significativamente ao longo do tempo decorrentes de alterações das condições de oxigenação do aquífero.

Em todos os trabalhos consultados sobre a degradação da PAM, não foram encontrados evidências conclusivas reportando a produção do composto tóxico acrilamida, o que exclui a possibilidade da liberação deste composto no ambiente. Os produtos gerados pela degradação da PAM são essencialmente representados por ácidos orgânicos e amônio. A oxidação do $\mathrm{NH}_{4}{ }^{+}$liberado pela degradação do PAM produz o $\mathrm{NO}_{3}$ que representa um importante contaminante presente em águas subterrâneas. Em razão destes mecanismos, o principal cenário de contaminação gerado pela disposição do PAM é representado pela produção do nitrato em condições aeróbicas.

\section{CONCLUSÕES}

O Modelo Conceitual elaborado para disposição de LETAs em aterro, com enfoque na degradação de PAM, foi validado para esse estudo de caso. 0 modelo conceitual concebido mostrouse adequado para explicar as reações associadas à degradação da PAM em subsuperfície, e a consequente liberação de compostos nitrogenados para a água subterrânea. Os resultados apresentados neste trabalho indicam que concentrações elevadas de amônio e nitrato estão associadas às reações de degradação da PAM e que sua classificação como composto ambientalmente seguro deve ser revista. No modelo conceitual formulado, a flutuação do nível de água no aquífero representa o fenômeno mais importante nas reações associadas à degradação da PAM, o que é confirmado pelos dados apresentados para a área.

\section{AGRADECIMENTOS}

A Fundação de Amparo à Pesquisa do Estado de São Paulo - FAPESP - Processo n² 2013/01507-1, ao Conselho Nacional de Desenvolvimento Científico e Tecnológico - CNPq pela bolsa de doutoramento a um dos autores. 


\section{REFERÊNCIAS}

CETESB - Companhia Ambiental do Estado de São Paulo. Manual de gerenciamento de áreas contaminadas. São Paulo (SP), 2001.

DAI, X., LUO, F; ZHANG, D.;DAl, L.; CHEN, Y.; DONG, B. WasteActivated Sludge Fermentation for Polyacrylamide Biodegradation Improved by Anaerobic Hydrolysis and Key Microorganisms Involved in Biological Polyacrylamide Removal. Scientific Reports, p.1-13, 2015.

FREITAS, W.S.; OLIVEIRA, R.A.; CENCON, P.R.; PINTO, F.A.; GALVÃO, J.C.C. Efeito da aplicação de água residuária de suinocultura sobre a produção de milho para silagem. Revista brasileira de Engenharia Agrícola e Ambiental, Campina Grande, v.8, n.1, p.120-125, 2004.

DENTEL, S. K. Evaluation and role of rheological properties in sludge management. Water Science and Technology - Sludge Rheology Selected Proceedings of the International Workshop on the Rheology of Sludges, 17 March 1997, Bari, Italy; Edited by P. Balmer, L. Spinosa, J.B. Bien, E.S. Kempa. v.36, n.11, p.18, 1997.

EL-MAMOUNI, R. Combining photolysis and bioprocesses for mineralization of high molecular weight polyacrylamides. Biodegradation, v. 13, n. 4, p. 221-227, 2002.

GUEZENNEC, A. Transfer and degradation of polyacrylamidebased flocculants in hydrosystems: a review. Environmental Science and Pollution Research, v. 22, n. 9, p. 6390-6406, 2015.

JOSHI, S. ABED, J., MM, R. Biodegradation of polyacrylamide and its derivatives. Environmental Processes, v. 4, n. 2, p. 463-476, 2017.

MOLAK, V. Acrylamide: a review of the literature. $\mathrm{NIOH}$ and $\mathrm{NIOSH}$ basis for an occupational health standard. Atlanta, Georgia: US Department of Health and Human Services, 1991.

MOUSSAS, P. A.; ZOUBOULIS, A. I. A New Inorganic-Organic Composite Coagulant, Consisting of Polyferric Sulphate (PFS) and
Polyacrylamide (PAA). Water Research, v. 43 , n. 14 , p. 3511 3524, 2009.

MUCHIMBANE, A.B.D.A. Avaliação da influência da disposição de lodo gerado por estação de tratamento de água (ETA) sobre a qualidade do solo e da água subterrânea na área da barragem Taiaçupeba, Suzano, SP. Tese de Doutorado, Instituto de Geociências, Universidade de São Paulo. 222p. São Paulo, 2016.

PEI, Y.; ZHAO, L.; DU, G.; Li, N.; XU, K.; YANG, H. Investigation of the degradation and stability of acrylamide-based polymers in acid solution: Functional monomer modified polyacrylamide. Ke Ai Advancing Research Envolvind Science, Petroleum n. 2, p. 399-407, 2016.

NAKAMIYA, K; KINOSHITA, S. Isolation of polyacrylamide-degrading bacteria. Journal of fermentation and bioengineering, v. 80 , n. 4, p. 418-420, 1995.

SEYBOLD, C. A. Polyacrylamide review: soil conditioning and environmental fate. Communications in soil science and plant analysis, v. 25, n. 11-12, p. 2171-2185, 1994.

SLATTER, P. T. The rheological characterisation of sludges. Water Science and Technology. V. 36, n.11, p.9-18, 1997.

THAMDRUP, B. New pathways and processes in the global nitrogen cycle. Annual Review of Ecology, Evolution, and Systematics. N.43, p.407-428, 2012.

WEN, Q. Biodegradation of polyacrylamide by bacteria isolated from activated sludge and oil-contaminated soil. Journal of Hazardous Materials, v. 175, n. 1-3, p. 955-959, 2010.

TSUTIYA, M.T.; HIRATA, A.Y. Aproveitamento e Disposição Final de Lodos de Estação de Tratamento de Água do Estado de São Paulo. In: CONGRESSO BRASILEIRO DE ENGENHARIA SANITÁRIA E AMBIENTAL, 21, 2001, João Pessoa. Anais eletrônicos. Disponível em: <http://www.bvsde.paho.org/bvsaidis/caliagua/brasil/i-025.pdf>. Acesso em: 02 abr. 2015.

ZHOU, J.; LIU, F.; PAN, C. Effects of Cationic Polyacrylamide Characteristics on Sewage Sludge Dewatering and Moisture Evaporation. PLOS ONE, v..9, n.5, 2014. 